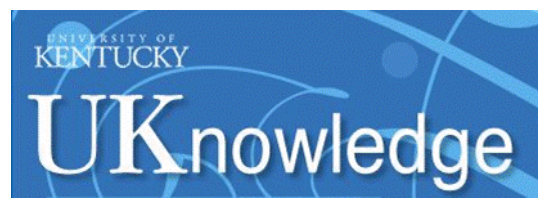

University of Kentucky

UKnowledge

$1-2008$

\title{
Obesity, Hypertension, and Mental Health Evaluation in Adolescents: A Comprehensive Approach
}

\author{
Stefan G. Kiessling \\ University of Kentucky, stefan.kiessling@uky.edu \\ Kimberly K. McClanahan \\ University of Kentucky \\ Hatim A. Omar \\ University of Kentucky, hatim.omar@uky.edu
}

Follow this and additional works at: https://uknowledge.uky.edu/pediatrics_facpub

Part of the Mental and Social Health Commons, and the Pediatrics Commons

Right click to open a feedback form in a new tab to let us know how this document benefits you.

\section{Repository Citation}

Kiessling, Stefan G.; McClanahan, Kimberly K.; and Omar, Hatim A., "Obesity, Hypertension, and Mental Health Evaluation in Adolescents: A Comprehensive Approach" (2008). Pediatrics Faculty Publications. 78.

https://uknowledge.uky.edu/pediatrics_facpub/78

This Article is brought to you for free and open access by the Pediatrics at UKnowledge. It has been accepted for inclusion in Pediatrics Faculty Publications by an authorized administrator of UKnowledge. For more information, please contact UKnowledge@lsv.uky.edu. 
Obesity, Hypertension, and Mental Health Evaluation in Adolescents: A Comprehensive Approach

\section{Digital Object Identifier (DOI)}

http://dx.doi.org/10.1515/IJAMH.2008.20.1.5

\section{Notes/Citation Information}

Published in International Journal of Adolescent Medicine and Health, v. 20, no. 1, p. 5-15.

(c) Freund Publishing House Ltd.

The copyright holder has granted permission for posting the article here.

Reprinted as a book chapter in Adolescence and Chronic Illness. A Public Health Concern. Hatim Omar, Donald E. Greydanus, Dilip R. Patel, \& Joav Merrick, (Eds.). p. 189-200. 


\section{Obesity, hypertension, and mental health evaluation in adolescents: A comprehensive approach}

\section{Stefan G Kiessling, $\mathrm{MD}^{\prime}$, Kimberly $\mathrm{K}$ McClanahan, $\mathrm{PhD}^{2}$ and Hatim A Omar}

'Division of Nephrology and ${ }^{2}$ Division of Adolescent Medicine, Department of Pediatrics, Kentucky Children's Hospital, Lexington, Kentucky, United States

Abstrac: The global epidemic of childhood and adolescent obesity in developing and developed countries has become a major public health concern. Given the relation between obesity and hypertension as documented in several landmark studies, it is no surprise that as the prevalence of obesity has increased in the pediatric population, the rates of hypertension have also increased substantially. Hypertension is one of the most important risk factors for cardiovascular diseases and stroke; therefore, evaluation and initiation of appropriate treatment are extremely important in the pediatric population. Evaluation for secondary causes of hypertension, including renovascular, renoparenchymal, and endocrine disease is the approach most commonly used in healthcare settings, with the goal to detect abnormalities that already have or might, if left unrecognized, affect the physical health of the child in the future. Children and adolescents are commonly evaluated for organic disease even in situations in which secondary hyperiension is unlikely and overweight or obesity is most likely the primary factor contributing to hypertension. Psychological and psychosocial factors, which may play an important role in the etiology of obesity and related blood pressure elevation, are often addressed inadequately or completely ignored, potentially reducing long-term therapy success and increasing the incidence of avoidable complications. It is proposed that a comprehensive evaluation by a behavioral health provider will improve outcomes and potentially reduce long-term morbidity and hypertension-related end organ disease. A framework for mental health evaluation is provided.

Keywords: Obesity, adolescent, hypertension, mental health, behavioral health

Correspondence: Hatim Omar, MD, Professor, Pediatrics \& Obstetrics/Gynecology, Director of Adolescent Medicine and Young Parent Program, J422 Kentucky Clinic, University of Kentucky, Lexington, KY 40536-0284, USA. Tel: 859-323-5643; Fax: 859-257-7706; Email: haomar2@ uky.edu

Submitted: August 15, 2007. Revised: September 17, 2007. Accepted: September 21, 2007.

\section{INTRODUCTION}

Obesity has become one of the most common diseases and disease-associated conditions in the United States (US) and other countries. We should note that overweight and obesity are usually defined as a body mass index (BMI) equal to or greater than the $95^{\text {th }}$ percentile, compared with pediatric population reference data when plotted on the appropriate age and gender chart. Children and adolescents with a BMI between the $85^{\text {th }}$ and $95^{\text {th }}$ percentile are considered at risk for obesity according to the Centers for Disease Control and Prevention (CDC). Unless otherwise noted, overweight and obesity will be defined as such throughout the remainder of this article.

In the year 2000 , estimates were that obesity would soon surpass tobacco smoking as the leading cause of preventable death in the United States (1). Also suggested is that today's young people may, on average, live 
less healthy and ultimately shorter lives than their parents because of overweight and obesity. In fact, this epidemic may reverse the modem era's steady increase in life expectancy (2-3). Further estimated is that, as this century progresses, more people will die from the complications of over-nutrition than from starvation (4). Between 1980 and 2002 , obesity prevalence doubled in adults age 20 years or older, and over-weight prevalence tripled in children and adolescents aged 6 to 19 years (5-7). Comparing the results obtained from the 2003-2004 National Health and Nutrition Examination Survey (NHANES) with the results from the NHANES survey in $1999-2000,17.1 \%$ vs. $13.9 \%$, respectively, of children and adolescents in the US were overweight (defined in this analysis as $95^{\text {th }}$ percentile of the sex-specific BMI). For female children and adolescents, the percenttage overweight increased from $13.8 \%$ in $1999-2000$ to $16.0 \%$ in $2003-2004$; for male children and adolescents, the increase went from $14.0 \%$ to $18.2 \%(6)$.

Obesity is reaching epidemic proportions and is seen at progressively younger ages. Several critical and vulnerable developmental periods, including infancy, early school age (adiposity rebound), and adolescence, have been discussed to play a role in the pathogenesis of obesity (8-9). Addressing obesity at the earliest age possible is important because most obese preadolescent children and at least $70 \%$ of obese adolescents will remain obese into adulthood (10), significantly increasing the chances of obesity-related disease in adulthood if those diseases have not had childhood onset. More than $10 \%$ of schoolage children are overweight or obese worldwide, with the Americas reporting rates as high as $32 \%$ (10). According to the 2005 Youth Risk Behavior Survey, a national probability sample of $9^{\text {th }}$ to $12^{\text {th }}$ graders that assesses risk behaviors and risk factors (data from CDC, 2006), approximately $16 \%$ of students nationally were at risk for overweight, and 13\% were already obese. In contrast, Kentucky students, the state in which we practice, showed $17^{\circ}:$ of students at risk for overweighe, comparable to the national sample, but almost $16 \%$ were already obese, significantly higher than the national statistics.

Nutrition and exercise, important variables in overweight and obesity, were also assessed in Kentucky youth and found lacking. In terms of the nutritional value of food and beverages consumed, Kentucky youth, in contrast to the national sample, drank significantly less fruit juice, ate significantly fewer fruits, green salads, carrots, and significantly more potatoes. Additionally, Kentucky youth were significantly less likely to eat five or more servings per day of fruits and vegetables (data from CDC 2006). The findings regarding exercise were equally alarming. According to CDC data (2006). Kentucky youth, in contrast to the national sample, exercised significantly less (e.g., aerobic exercise, non aerobic exercise, moderate physical activity, attendance at physical education classes).

Other alarming findings from a study by Omar and Rager (11) regarding Kentucky youth and obesity are that these youth misperceive the degree to which they are overweight. In looking at $6^{\text {th }}$ and $9^{*}$ grade samples whose BMI was assessed objectively and who were asked about their weight, $23 \%$ of $9^{\text {th }}$ grade females and $1 \%$ of $6^{*}$ grade females perceived themselves as overweight. whereas $50 \%$ and $31 \%$, respectively, met objective measures for overweight or obesity, i.e., BMI. Males had similar misperceptions with $45 \%$ of $9^{\text {th }}$ grade and $34 \%$ of $6^{\text {m }}$ grade males actually at risk for overweight or obese, whereas only $9 \%$ and $1.5 \%$, respecttively, perceived them-selves to be so.

One of the most important issues noted in 
the recent past is that maintaining a positive energy balance, even if only to a minimal degree, will, in the long term, lead to weight gain and obesity. If endogenous causes of childhood obesity are eliminated, then lack of physical exercise, sedentary behavior, and poor dietary choices are the most common risk factors for weight gain, potentially leading (or contributing) to hypertension and/or other obesity-related disease states. Pinhas-Hamiel (12) noted that, "life-stylerelated diseases are no longer the exclusive domain of adult medicine." The yearly rate of deaths related to complications of obesity is rising, and young adults are in the highest risk group to develop obesity.

\section{Hypertension in children and adolescents} As with overweight and obesity, the prevalence of hypertension has also risen in children and adolescents (13) and is predictive of hypertension in adulthood (14). The Fourth Task Force Report (15) defines hypertension as three independent blood pressure readings above the $95^{\text {th }}$ percentile adjusted for height and age reference values of the child. The report introduced the $99^{\text {th }}$ percentile of blood pressure readings as a marker of more severe (stage II) hypertension with the aim to simplify management and treatment decisions for the healthcare provider. Because elevated blood pressure can cause systemic symptoms but can be a secondary finding in acute illness as well, once the child has completely recovered a high index of suspicion should be kept, and elevated blood pressure readings should be followed by repeated measurements.

Hypertension is a known risk factor for cardiovascular and cerebrovascular disease, and the criteria for the evaluation of secondary causes have been established and refined, most recently in 2004 in the Fourth Task Force Report (15). Guidelines for the basic evaluation of secondary causes or early signs of end-organ damage in obese and non-obese children with hypertension are outlined in table 1. Most providers caring for children with hypertension feel that marked blood pressure elevation in younger children is an ominous finding and are very aggressive in ruling out secondary organic causes, especially in the absence of overweight. The relation between increased body weight and higher blood pressure readings was demonstrated in the past 16 and overweight children with documented blood pressure elevations might benefit from a comprehensive approach to weight control after secondary causes of hypertension have been ruled out.

The relation between obesity and hypertension in children and adolescents

Several well designed studies have documented the association between hypertension and obesity as well as other cardiovascular risk factors (17-19). Overweight children have higher blood pressures compared to normal weight controls and as many as $30 \%$ of children with a BMI greater than the 95th percentile have hypertension (19-20). In 2002, Sorof et al reported a threefold higher prevalence of systolic hypertension on the first screening in obese versus non obese children in a cohort of 2460 individuals between 12 and 16 years of age (19).

In most obese individuals seen in physicians' offices for evaluation of hypertension, excessive weight gain reflects a long-term problem rather than a shortterm change. Poorly controlled diet and lack of exercise are oftentimes easily identified as factors responsible for weight gain due to a positive energy balance. The lack of recognition of obesity as a problem by families and providers, and low counseling rates continue to be ongoing problems 
Table 1. Guidelines for the evaluation of hypertension (HTN) in children and adolescents

1. All children with persistent blood pressures equal to are greater than the $95^{\text {th }}$ percentile

a. Renal function and electrolytes

b. Urinalysis and urine culture

c. Complete blood count

d. Fasting lipid profile

c. Thyroid function studies

f. Retinal exam

g. Echocardiogram

h. Renal Doppler ultrasound

2. Overweight patients with BP at $90-94^{\text {th }}$ percentile, family history of cardiovascules disease. children with chronic renal disease

a. Fasting lipid panel and serum glucose

3. History of loud snoring/breath holding

a. Polysomnography

4. Young children with stage $1 \mathrm{HTN}$ and any child or adolescent with stage $2 \mathrm{HTN}$

a. Plasma renin activity and aldosterone level

5. Renovascular imaging (renal scan, MRA, arteriography)

a. Plasma and urine steroid levels

b. Plasma and urine catecholamines

c. Suspected white-coat HTN or more information needed on BP partem

d. $24 \mathrm{hr}$ ambulatory BP measurement

6. Children with comorbid risk factors and BP readings between $90^{\text {th }}$ and $94^{\text {th }}$ percentile

a. Echocardiogram

b. Retinal exam

Other tests might be necessary but need to be discussed on an individualized basis.

(21). Medical complications, including type Il diabetes, hypercholesterolemia, and obstructive sleep apnea, to name a few, are well-known complications of obesity.

Morrison et al (22-23) have shown that overweight girls and boys have a much higher prevalence of several cardiovascular risk factors compared with the average expected frequency, suggesting that health problems related to obesity are common and will significantly make an impact on future healthcare-related costs. Weight management is recommended in both stages of hypertension, but in clinical practice, the rate of successful weight loss is quite low. With continued blood pressure readings above the $95^{\text {th }}$ percentile, the Fourth Task Force Report (15) recommends initiating pharmacologic therapy. Even though this approach certainly reduces the risk of blood pressure-related long-term complications if blood pressure control is achieved, pharmacologic therapy does not affect overweight and obesity and may actually decrease the incentive to lose weight, especially if mild symptoms like blood-pressure-related headaches are controlled.

A timely and thorough evaluation for secondary causes of hypertension and the initiation of non-pharmacologic or pharmacologic therapy are recommended by most health care providers involved in the care of 
those children with consistently elevated blood pressure (24-25). This approach is especially important for children who already have evidence of early end organ damage or are at high risk. The Fourth Task Force Report (15) recommends a baseline evaluation of secondary causes of hypertension in almost all overweight or obese children, as well as in all non obese children and teenagers with blood pressures above the $95^{\text {th }}$ percentile adjusted for the appropriate height and age percentile curve.

\section{The role of mental and behavioral health} The Fourth Task Force Report (15) recognizes the strong association between high blood pressure and overweight and obesity, as well as the significant increase in the prevalence of overweight children and provides very detailed recommendations for the evaluation of organic disease related to hypertension. The report, however, presents no clear guidelines regarding the assessment of mental and behavioral health issues in the hypertensive, obese child, even though the report clearly regards weight loss as "the primary therapy for obesityrelated hypertension". The association of mental health, obesity, and hypertension in adults is well known, and even though data in the pediatric population are quite limited (26-28), it appears to be somewhat intuitive that a similar relation would be present in children and adolescents who struggle with ovenweight and obesity, although the data are somewhat contradictory.

Several studies have documented a clear correlation between depression and obesity in adolescents (26-28). Goodman et al (29) have shown in a nationally representative, longitudinal study of over 9,000 adolescents that depressed mood in non-obese individuals is associated with the development of obesity at one year and worsening obesity in baseline obese participants, suggesting that depression may precede obesity. Other studies using community samples of obese vs non obese adolescents have found no differences between the two groups in depressive symptoms (30).

Swallen et al (31) found a statistically significant relation between BMI and general physical health in adolescents from age 12 to 20 years, but only young adolescents (12-14 years of age) evidenced a deleterious impact on emotional health as reported by depression and/or low self esteem. Several studies, including a recent one by Daniels (26), failed to confirm a relation between obesity and symptoms of depression in adolescents. Recent studies have also focused on BMI as a potential link between depression and the risk for hypertension. Kabir et al (28) have shown in a study of more than 1000 mostly adult participants, that BMI can be an intermedjate varjable linking depression and hypertension because when compared with obese individuals, individuals with the same depression score and no obesity had a lower likelihood to be hypertensive. Thus, the relation between depressive symptoms and overweight and obesity in children and adolescents is not completely clear, although depression appears to play a role in the mental health of a certain subpopulation of obese adolescents.

Studies on self-esteem in obese children and adolescents also report inconsistent results. Some studies have shown moderately lower self-esteem in obese children and adolescents than in their non obese peers (32-33), whereas others found no difference between population-based groups of obese children and their non-obese peers (34-35). Obese females are also at greater risk for self-esteem problems because body image is so important to self-image (32). In clinical populations, a clear relation exists between obesity and self-esteem in children 
and adolescents, with the more obese children having lower self-esteem (35). One hypothesis is that clinically referred children re-present a subgroup of obese children associated with especially low self-esteem (36).

Eating disorders are associated with obesity (37). Britz et al (38) reported that the rate of eating disorders, including bulimia nervosa, eating disorders not otherwise specified, and anorexia nervosa, was six times higher in an obese patient group than in a population-based control group. Sixty percent of females and $35.5 \%$ of males reported binge eating episodes.

Stigmatization of obese children and adolescents is also significant and has long been a part of western culture (39). Studies have shown that children as young as three years of age begin to have negative attitudes toward overweight and obesity. When given different methods for assessing stigmatizing attitudes, these children ascribe negative characteristics to overweight targets, including mean, ugly, stupid, and sloppy, compared with non-ovenweight targets (40). These trends tend to worsen as children get older (41). Such stereotypes are born out in real life when studies show that US women who were obese adolescents become adults with lower educational attainment, lower paying jobs, higher rates of poverty, and less likelihood of marriage in comparison with thinner women (42-43). Obese youth have greater difficulty in gaining admission to college, although there is no indication that they are less apt to be able to complete the course work (39).

\section{Evaluation of mental health}

Obese children and adolescents should be thoroughly evaluated to identify any psychological conditions that may affect the course of treatment (36), especially when there are other complicating medical factors. However, routine evaluation of mental and behavioral health is not in the recommended work-up for hypertension in obese adolescents, leaving an important gap in the evaluation. The Fourth Task Force Report (15) mentions weight loss and opti-mizing blood pressure control by behavior modjfication but does not provide specific guidelines on how to achieve this goal. This could be part of the reason why health care providers are unsure about how and when to evaluate mental and behavioral health in this patient population.

Additionally, most pediatric health care providers are not trained to assess mental health issues and may have limited experience in daily practice in addressing mental health-related problems. Other factors, including limited visit time and lack of established office strategies (24), may also contribute to the lack of detection of the psychological and psychosocial factors leading to obesity or originating from it. Additionally, pediatricians may directly or indirectly express "fatism," which may contaminate the relationship with their young patients and is particularly true with younger, obese patients where parent-bashing or blaming is common (36).

Jonides et al (44) reported on the results of a questionnaire to pediatricians asking about the routine evaluation of various psychological and emotional factors, including self-esteem, eating disorders, concem about weight, family dynamics, and history of abuse. The authors showed that by far not every provider asks and elaborates on all of those important factors. Friedman (45) suggested that pediatricians are in an ideal position to detect psychological issues in young people, and they should be better trained to probe for and to recognize signs of major mental illnesses. Weitzman and Leventhal (46) concluded that the pediatric practice setting is an optimal environment for behavioral health screening if the 
currently available tools are used effectively. However, training is lacking in these areas.

Given that most providers specializing in childhood and adolescent hypertension are not trained in mental and behavioral health evaluations, a pediatric trained psychologist familiar with evaluation and treatment options of various mental and behavioral health conditions in children and adolescents could add significant value to the team caring for this particular patient subset. It is postulated that the evaluation and treatment of underlying psychological and behavioral problems by a health care provider trained in adolescent mental health will aid in the reduction of hypertension and obesity related mortality in children and adolescents.

\section{Recommendations for evaluating mental health}

No consensus recommendation has emerged for the evaluation of mental health in overweight adolescents with and without hypertension, and no studies comparing different methods for the psychiatric assessment of affected children are available (36). An expert committee recommendation on obesity evaluation and treatment by Barlow and Dietz (47) suggested that asking the right questions in "objective, non accusatory language" would help to establish a basis of trust between family and provider, which is key to long-term, successful management. Additionally, the use of well-validated instruments for evaluation is important.

In our Pediatric Hypertension Clinic, every child with a BMI greater than the $85^{\text {th }}$ percentile and documented blood pressure readings above the $90^{\text {th }}$ percentile is offered an evaluation by a pediatric psychologist at the time of the initial visit. The psychologist is involved at the time of the first follow-up visit for (borderline) hypertension, after all laboratory data are collected and secondary causes of hypertension have been assessed by the Pediatric Specialist.

At the initial visit with the pediatric psychologist, a thorough psychiatric, psychological and family history regarding the patient is taken. As rapport is established, questions are asked regarding the patient's weight and whether there are concerns about weight, weight gain or loss, eating issues, and psychosocial issues associated with being overweight (does the patient have friends, is he/she teased at school, depressive or other symptoms associated with overweight).

A number of paper and pencil instruments are completed by the child and parents to assess psychological distress in the child or adolescent. As noted earlier, a high rate of depression and other psychological issues have been found more consistently among obese children than among children of normal weight (28). The Children's Depression Inventory (CDI), a 27-item, symptomoriented scale for children ages 6-17 years is used to assess level of depression in children in the clinic setting (48). The CDI, a highly reliable and valid measure (49), has been used effectively in several studies with obese children (50-51). Because the CDI is a selfreport measure, it is supplemented by a parent-completed Child Behavior Checklist (52) to obtain corroborating or conflicting data from parents. Issues regarding eating are measured through completion of a version of the Eating Attitude Test (53-54). This test is a 6-point, forced choice, selfreport inventory that measures dieting behaviors, food preoccupation, anorexia, bulimia, and concerns about being overweight. Versions for teenagers and younger children (chEAT), have demonstrated concurrent and predictive validity as well as reliability (54). Finally, for overall symptom assessment, younger children (9-12 years) will complete the Millon Pre-adolescent Clinical Inventory (M-PACl), and adolescents (13-19 years) will complete the Millon 
Adolescent Clinical Inventory (MACl). Both instruments are designed to identify psychological problems quickly and accurately, and look at both emerging personality patterns and acute psychological symptoms.

Effects of stable mental health on outcome Addressing mental health by correct and timely diagnosis and intervention can be of significant importance in improving the outcome of obesity-related hypertension in children and adolescents. In adolescents dealing with hypertension, one certainly wonders if undiagnosed and non-treated mental health problems, including anxiety and depression in an asymptomatic individual, can lead to medical non-compliance and worsen hypertension and related end organ disease. Additionally, the correct diagnosis and therapy of mental health problems, if associated with obesity and hypertension, can improve weight management and decrease the need for pharmacologic therapy to decrease risk of weight and blood pressure related complications.

Data on the outcome of evaluation and treatment of behavioral health in obese hypertensive children and adolescents are limited and purely based on non-controlled observation. Our strategy has helped to identify children with behavioral health issues that would likely have gone unrecognized if not for the assessment and counseling by a pediatric psychologist. Several children have achieved better weight control and improvement of blood pressure readings after a behavior health specialist was involved. Clinical trials are currently underway and we hope to present broader, controlled data in the near future.

\section{FUTURE DIRECTIONS}

Obesity and related hypertension have become major problems in the developed and developing world in recent years. Pre- venting obesity would likely signifieantly reduce the incidence of hypenension and related long-term organ injury including diabetes mellitus and cardiovascular as well as cerebrovascular discase.

Adolescents are a high risk group for developing obesity and hypertension, which is, in part, due to the vulnerable developmental stage. The knowledge that most overweight and obese teenagers will be unsuccessful in their attempts-if they are even considered-to lose weight and move on to become overweight and obese adults has shifted the focus clearly toward primary prevention of obesity. Primary prevention is certainly the best strategy but as of today, obesity and its potential complications are more prevalent than ever and must be addressed more aggressively and comprehensively. To improve obesity-related morbidity and mortality in this age group. providers involved in their care have to develop a better understanding and an increased focus on mental health in addition to physical health. One strategy is a comprehensive team approach, including a mental health specialist who not only addresses those issues in the patient and family but also teaches the provider better strategies for initial screening. The experienre in our practice has been very positive, but more long-term data to suppont our approach are certainly necessary.

\section{REFERENCES}

1. Mokdad AH, Marks JS, Stroup DF, Gerberding JL. Actual causes of death in the United States, 2000. JAMA 2004;291:1238-45.

2. Daniels SR. The consequences of childhood overweight and obesity. Future Child 2006;16:47-67.

3. Olshansky SJ, Passaro DJ, Hershow RC, Layden J, Carnes BA, Brody J et 
al. A potential decline in life expectancy in the United States in the $21^{\text {th }}$ century. N Engl J Med. 2005;352(11): 1138-45.

4. Rossner S. Obesity: The disease of the twenty-first century. Int J Obes Relat Metab Disord 2002;26 Suppl 4: S2-4.

5. Hedley AA, Ogden $C L$, Johnson $C L$, Carroll MD, Curtin LR, Flegal KM. Prevalence of overweight and obesity among US children, adolescents, and adults, 1999-2002. IAMA 2004;291: 2847-50.

6. Ogden CL, Carroll MD, Curtin LR, McDowell MA, Tabak CJ, Flegal KM. Prevalence of overweight and obesity in the United States, 1999-2004. JAMA 2006;295:1549-55.

7. Ogden $C L$, Flegal KM, Carroll MD, Johnson CL. Prevalence and trends in overweight among US children and adolescents, 1999-2000. JAMA 2002; 288:1728-32.

8. Dietz WH. Critical periods in childhood for the development of obesity. Am J Clin Nutr 1994;59:955-9.

9. Dietz WH, Robinson TN. Clinical practice. Overweight children and adolescents. N Engl J Med 2005;352: 2100-9.

10. Reill y JJ. Obesity in childhood and adolescence: evidence based clinical and public health perspectives. Postgrad Med J 2006;82: 429-37.

11. O mar HA, Rager K. Prevalence of obesity and lack of physical activity among Kentucky adolescents. Int J Adolesc Med Health 2005; 17:79-82.

12. Pinhas-Hamiel $O$, Zeitler P. "Who is the wise man?-The one who foresees consequences:". Childhood obesity, new associated comorbidity and prevention. Prev Med 2000;31(6): 702-5.

13. Mun tner $P$, He J, Cutler JA, Wildman
RP, Whelton PK. Trends in blood pressure among children and adolescents. JAMA 2004;291:2107-13.

14. Bao W, Threefoot SA, Srinivasan SR, Berenson GS. Essential hypertension predicted by tracking of elevated blood pressure from childhood to adulthood. Am J Hypertens 1995;8: 657-65.

15. National High Blood Pressure Education Program Working Group on High Blood Pressure in Children and Adolescents. The fourth report on the diagnosis, evaluation, and treatment of high blood pressure in children and adolescents. Pediatrics 2004;114(2): 555-76. [Full report available from: http://www.nhlbi.nih.gov/health/prof/h eart/hbp/hbp_ped.pdf]

16. $L$ uepker RV, Jacobs DR, Prineas RJ, Sinaiko AR. Secular trends of blood pressure and body size in a multiethnic adolescent population: 1986 to 1996. J Pediatr 1999;134:668-74.

17. Freed man DS, Dietz WH, Srinivasan $S R$, Berenson GS. The relation of overweight to cardiovascular risk factors among children and adolescents: the Bogalusa Heart Study. Pediatrics 1999;103:1175-82.

18. Israeli E, Schochat $T$, Korzets $Z$, Tekes-Manova D, Bernheim J, Golan E. Prehypertension and obesity in adolescents: a population study. Am J Hypertens 2006;19:708-12.

19. Sorof J, Daniels S. Obesity hypertension in children: a problem of epidemic proportions. Hypertension 2002;40: 441-7.

20. Sorof JM, Poffenbarger T, Franco $K$, Bernard L, Portman RJ. Isolated systolic hypertension, obesity, and hyperkinetic hemodynamic states in children. J Pediatr 2002;140:660-6.

21. Galuska DA WJ, Serdula MK, Ford ES. Are health care professionals advising 
obese patients to lose weight? JAMA 1999;282:1576-8.

22. Morrison JA, Barton BA, Biro FM, Daniels SR, Sprecher DL. Overweight, fat patterning, and cardiovascular disease risk factors in black and white boys. J Pediatr 1999;135:451-7.

23. Morrison JA, Sprecher DL, Barton BA, Waclawiw MA, Daniels SR. Overweight, fat patterning, and cardiovascular disease risk factors in black and white girls: The National Heart, Lung, and Blood Institute Growth and Health Study. J Pediatr 199;135:458-64.

24. L uma GB, Spiotta RT. Hypertension in children and adolescents. Am Fam Physician 2006;73:1558-68.

25. Pappa dis SL, Somers MJ. Hypertension in adolescents: a review of diagnosis and management. Curr Opin Pediatr 2003;15:370-8.

26. $\mathrm{D}$ aniels $\mathrm{J}$. Weight and weight concerns: are they associated with reported depressive symptoms in adolescents? J Pediatr Health Care 2005; 19:33-41.

27. Heo M, Pietrobelli A, Fontaine KR, Sirey JA, Faith MS. Depressive mood and obesity in US adults: comparison and moderation by sex, age, and race. Int J Obes (Lond) 2006;30:513-9.

28. Kabir AA, Whelton PK, Khan MM, Gustat J, Chen W. Association of symptoms of depression and obesity with hypertension: the Bogalusa Heart Study. Am J Hypertens 2006; 19:639-45.

29. Goodma n E, Whitaker RC. A prospective study of the role of depression in the development and persistence of adolescent obesity. Pediatrics 2002; 110:497-504.

30. Wardle J, Williamson $S$, Johnson $F$, Edwards C. Depression in adolescent obesity: Cultural moderators of the association between obesity and depressive symptoms. Int J Obesity 2006;30:634-43.

31. S wallen KC, Reither EN, Hass SA. Meier AM. Overweight, obesity, and health-related quality of life among adolescents: the National Longitudinal Study of Adolescent Health. Pediatrics 2005:115:340-7.

32. Pesa JA, Syre TS, Jones E. Psychosocial differences associated with body weight among female adolescents: The importance of body image. J Adolesc Health 2000;26:330-7.

33. Straus s RS. Childhood obesity and self-esteem. Pediatrics 2000;105:1.5.

34. R enman C, Engstrom I, Silfverdal SA. Aman J. Mental health and psychosocial characteristics in adolescent obesity: A population-based case-control study. Acta Paediatr 1999;88:9981003.

35. Ru mpel C, Harris TB. The influence of weight on adolescent self-esteem. J Psychosom Res 1994;38:547-56.

36. Za metkin AJ, Zoon CK, Klein HW, Munson S. Psychiatric aspects of child and adolescent obesity: a review of the past 10 years. I Am Acad Child Adolesc Psychiatry 2004;43:134-50.

37. N eumark-Sztainer $D$, Story $M$, French SA, Falkner NH, Beuhring T, Resnick MD. Sociodemographic and personal characteristics of adolescents engaged in weight loss and weight/muscle gain behaviors: Who is doing what? Prev Med 1999;28:40-50.

38. Britz B, Siegfried W, Ziegler A, Lamertz C, Herpertz-Dahlmann BM, Remschmidt $H$, et al. Rates of psychiatric disorders in a clinical study group of adolescents with extreme obesity and in obese adolescents ascertained via a population based study. Int J Obesity 2000; 24: 1707-14. 
39. Puhl RM, Latner JD. Stigma, obesity, and the health of the nation's children. Psychol Bull 2007;133:557-580.

40. Cramer P, Steinwert T. Thin is good, fat is bad: how early does it begin? J Appl Dev Psychol 1998;19:429-51.

41. Wardle J, Volz C, Golding C. Social variation in attitudes to obesity in children. Int J Obes 1995;19:562-9.

42. Dietz WH. Periods of risk in childhood for the development of adult obesity-what do we need to learn? J Nutr 1997;127:1884S-6S.

43. Maf fies $C$, Tato $L$. Long-term effects of childhood obesity on morbidity and mortality. Horm Res 2001;55(suppl 1):SS42-5.

44. J onides L, Buschbacher V, Barlow SE. Management of child and adolescent obesity: psychological, emotional, and behavioral assessment. Pediatrics 2002; 110:215-21.

45. Friedman RA. Uncovering an epidemic-screening for mental illness in teens. N Engl J Med 2006;355:27179.

46. Weitz man CC, Leventhal JM. Screening for behavioral health problems in primary care. Curr Opin Pediatr 2006; 18:641-8.

47. Barlow SE, Dietz WH. Obesity evaluation and treatment: Expert Committee recommendations. The Maternal and Child Health Bureau, Health Resources and Services Administration and the Department of Health and Human Services. Pediatrics 1998;102: E29.

48. Kovacs M. The Children's Depression Inventory (CDI). Psychopharmacol Bull 1985;21:995-8.

49. Kni ght D, Hensley VR, Waters B. Validation of the Children's Depression Scale and the Children's Depression Inventory in a prepubertal sample. J Child Psychol Psychiatry 1988;29: 853-63.

50. Shes low D, Hassink S, Wallace W, DeLancey $E$. The relationship between self-esteem and depression in obese children. Ann NY Acad Sci 1993; 699:289-91.

51. Wallace WJ, Sheslow D, Hassink S. Obesity in children: A risk for depression. Ann NY Acad Sci 1993; 699: 301-3.

52. Ac henbach TM, Ruffle TM. The Child Behavior Checklist and related forms for assessing behavioral/emotional problems and competencies. Pediatric Rev 2000;21:265-71.

53. Garner DM, Garfinkle PE. The eating attitudes test: An index of the symptoms of anorexia nervosa. Psychol Med 1979;9:273-9.

54. Malone y MJ, McGuire JB, Daniels SR. Reliability testing of a children's version of the Eating Attitude Test. J Acad Child Adolesc Psychiatry 1988; 27:541-3. 